\title{
TO STUDY THE RELATIONSHIP BETWEEN MICROALBUMINURIA AND ISCHAEMIC HEART DISEASE IN NON-DIABETIC SUBJECTS
}

Maneesh Kumar Varshney ${ }^{1}$, C. P. Meena ${ }^{2}$, Girish Chandra Verma 3 , S. R. Meena ${ }^{4}$, Abdul Wahid Qureshi ${ }^{5}$, Hemant Richhariya ${ }^{6}$

1 Postgraduate Resident, Department of Medicine, Government Medical College, Kota, Rajasthan.

2Professor, Department of Medicine, Government Medical College, Kota, Rajasthan.

3 Senior Professor and Unit Head, Department of Medicine, Government Medical College, Kota, Rajasthan.

${ }^{4}$ Senior Professor and HOD, Department of Medicine, Government Medical College, Kota, Rajasthan.

${ }_{5}^{5}$ Assistant Professor, Department of Medicine, Government Medical College, Kota, Rajasthan.

${ }_{6}^{6}$ Postgraduate Resident, Department of Medicine, Government Medical College, Kota, Rajasthan.

\section{BACKGROUND}

\section{ABSTRACT}

Microalbuminuria is known to be an independent risk factor for ischaemic heart disease in diabetics; however, its association in non-diabetics has not been addressed in detail.

Aims and Objectives- To determine an independent association between microalbuminuria and IHD in non-diabetic subjects.

\section{MATERIALS AND METHODS}

A descriptive study was conducted in the Department of Medicine, Government Medical College, Kota in the year 2017-18. 100 non-diabetic subjects with IHD attending the outpatient clinic or admitted as inpatients in the Medicine wards of MBS Hospital, Government Medical College, Kota who were diagnosed as first time reported case of IHD on the basis of inclusion criteria (Electrocardiographic changes and Cardiac Enzyme Estimation and the Rose questionnaire) and exclusion criteria were included. Statistical Analysis- Data was compiled in MS Excel and checked for its completeness, correctness and then it was analysed.

\section{RESULTS}

In the present study, out of 100 cases, 72 cases were male and 28 cases were female. In our study, age group 56 - 65 years constituted $38 \%$ of the cases. Out of the 100 cases, 77 cases (77\%) had microalbuminuria. Microalbuminuria is slightly higher in patients who presented with infarct pattern on ECG (78.2\%) compared to ischaemia pattern (74.2\%). Majority of patients had microalbuminuria level between $30-100 \mathrm{mg} /$ day. $82.1 \%$ of females had microalbuminuria $\geq 30 \mathrm{mg} /$ day compared to $75 \%$ of males in the present study. Hypertension was present in $58 \%$ of study subjects, in which females had higher percentage (Maleto-Females- $51.3 \%$ to $75 \%$ ). Total 70 patients had history of smoking, out of which $77.1 \%$ (54 patients) had Microalbuminuria as compared to 75.8\% non-smoker (22 patients) with Microalbuminuria. Mean Total Cholesterol, Mean Triglyceride and Mean LDL Cholesterol were higher in female in this study. Major dyslipidaemia was hypertriglyceridaemia in 34\% of cases and low HDL in $31 \%$ of cases, which is typical Indian profile pattern.

\section{CONCLUSION}

Microalbuminuria is positively associated with Ischaemic Heart Disease in non-diabetic subjects and can be regarded as an important additional risk factor for Ischaemic Heart Disease.

\section{KEY WORDS}

Ischaemic Heart Disease, Microalbuminuria, Non-Diabetics.

HOW TO CITE THIS ARTICLE: Varshney MK, Meena CP, Verma GC, et al. To study the relationship between microalbuminuria and ischaemic heart disease in non-diabetic subjects. J. Evolution Med. Dent. Sci. 2018;7(21):2562-2565, DOI: $10.14260 /$ jemds/2018/577

\section{BACKGROUND}

Ischaemic Heart Disease refers to disorders resulting from an imbalance between myocardial oxygen supply and demand. ${ }^{1}$ Cardiovascular disease is the leading global cause of death accounting for more than 17.3 million deaths per year, a number that is expected to grow to more than 23.6 million by 2030. IHD causes more death and disability and incurs greater economic cost than any other illness in the developed world. ${ }^{2}$

'Financial or Other Competing Interest': None.

Submission 13-04-2018, Peer Review 06-05-2018,

Acceptance 12-05-2018, Published 21-05-2018.

Corresponding Author:

Maneesh Kumar Varshney,

Room No. 23, PG 1 Hostel,

MBS Hospital Campus, Nayapura,

Kota-324001, Rajasthan.

E-mail: drmkvarshney1990@gmail.com

DOI: $10.14260 /$ jemds/2018/577
Risk factors for ischaemic heart disease include age, male gender, a positive family history of premature atherosclerotic disease, smoking, diabetes mellitus, hypertension, abnormalities of serum lipids. ${ }^{3}$ To reduce the burden of cardiovascular disease, management strategies are increasingly focusing on preventive measures by early detection of marker of atherosclerosis that's why intense discussion is going on Lipoprotein (a), ${ }^{4}$ C-Reactive Protein, 5,6 Fibrinogen, ${ }^{7}$ Homocysteine ${ }^{8}$ and Microalbuminuria. ${ }^{9}$

In this study, we specially focused on microalbuminuria which is gaining recognition as a simple marker of an atherogenic milieu.

Microalbuminuria is a well-accepted marker of micro and macrovascular damage in patients with diabetes mellitus. It gradually became increasingly evident that microalbuminuria is associated with an increased risk of cardiovascular disease even in non-diabetic patients. ${ }^{10}$ 
The aim of the study is to determine an independent association between microalbuminuria and IHD in nondiabetic subjects.

\section{MATERIALS AND METHODS}

This descriptive study was conducted in the Department of Medicine, Government Medical College, Kota in the year 2017 - 18. 100 non-diabetic subjects with Ischaemic Heart Disease attending the outpatient clinic or admitted as inpatients in the Medicine wards of MBS Hospital, Government Medical College, Kota who were diagnosed as first time reported case of Ischaemic Heart Disease.

\section{Inclusion Criteria}

The diagnosis of Ischaemic Heart Disease will be based on the 12-lead ECG, cardiac enzymes estimation and the Rose questionnaire.

\section{Exclusion Criteria}

1. Diabetic patients by ADA criteria.

2. Congestive cardiac failure at presentation.

3. Urine showing:

- Macroalbuminuria (dipstick positive albuminuria).

- $\mathrm{RBCs}>50 / \mu \mathrm{L}$.

- Leucocytes $>75 / \mu \mathrm{L}$.

4. Female patients with vaginal discharge.

\section{Test for Microalbumin}

24-hour urine albumin excretion estimation (Gold standard test for microalbuminuria) done by Esbach's Method.

\section{RESULTS}

100 patients fulfilling the criteria for study were included. The study was done over a period of one year. In the present study, out of 100 patients 72 were males and 28 were females.

\begin{tabular}{|c|c|c|c|}
\hline \multirow{2}{*}{ Age } & \multicolumn{2}{|c|}{ Sex } & \multirow{2}{*}{ Total } \\
\cline { 2 - 3 } & Male & Female & \\
\hline $26-35$ & 6 & 0 & 6 \\
\hline $36-45$ & 12 & 0 & 12 \\
\hline $46-55$ & 19 & 7 & 26 \\
\hline $56-65$ & 22 & 17 & 39 \\
\hline $66-75$ & 13 & 4 & 17 \\
\hline Total & $\mathbf{7 2}$ & $\mathbf{2 8}$ & $\mathbf{1 0 0}$ \\
\hline \multicolumn{3}{|c|}{ Table 1. Age and Sex Distribution } \\
\hline
\end{tabular}

The mean age of study population was $55.09 \pm 10.43$ years. It was $53.90 \pm 11.27$ years for males and $59.48 \pm 6.13$ years for females. Subjects in the age group of $56-65$ years constituted $38 \%$ of study group. Majority of females were aged above 55 years (75\%).

Family history of IHD was present in $38 \%$ of the cases.

History of smoking was present in $70 \%$ of the study subjects $(\mathrm{p}<0.0001)$. There was no female patient with history of smoking, whereas $97.2 \%$ of the male patients gave a history of smoking.

Hypertension was present in $58 \%$ of study subjects, in which Females had higher percentage (Male-to-Females $51.3 \%$ to $75 \%$ ). The Mean Systolic BP was $143.33 \pm 10.8$ in males and $149.71 \pm 11.19$ in females. The Mean Diastolic BP was $88.16 \pm 7.28$ in males and $89.21 \pm 8$ in females.
The Mean FBS was $99.12 \pm 7.71$ and Mean PPBS was $137.7 \pm 15.8$ in this study group.

\begin{tabular}{|c|c|c|c|}
\hline Lipid Parameter & $\begin{array}{c}\text { Male } \\
(\mathbf{n = 7 2})\end{array}$ & $\begin{array}{c}\text { Female } \\
(\mathbf{n = 2 8})\end{array}$ & Total \\
\hline $\begin{array}{c}\text { Total cholesterol } \\
(>200 \mathrm{mg} \%)\end{array}$ & $19(26.39 \%)$ & $9(32.14 \%)$ & $28(28 \%)$ \\
\hline $\begin{array}{c}\text { Triglyceride } \\
(>150 \mathrm{mg} \%)\end{array}$ & $18(25 \%)$ & $16(57.14 \%)$ & $34(34 \%)$ \\
\hline $\begin{array}{c}\text { HDL }(\mathrm{M}<40 \mathrm{mg} \%, \\
\text { F }<50 \mathrm{mg} \%)\end{array}$ & $6(8.3 \%)$ & $25(89.2 \%)$ & $31(31 \%)$ \\
\hline LDL (>150 mg\%) & $6(8.3 \%)$ & $2(7.1 \%)$ & $8(8 \%)$ \\
\hline \multicolumn{4}{|c|}{ Table 2. Abnormal Lipid Parameters } \\
\hline
\end{tabular}

In this study the major dyslipidaemia was hypertriglyceridaemia in 34\% of cases and low HDL in 31\% of cases, which is typical Indian lipid profile pattern.

Of the whole study the mean total cholesterol was $192.43 \pm 23.03$, mean triglyceride was $143.75 \pm 37.14$, mean HDL cholesterol was $41.94 \pm 3.80$ and mean LDL cholesterol was $122.31 \pm 21.06$.

\begin{tabular}{|c|c|c|}
\hline Microalbuminuria & Male (n= 72) & Female (n= 28) \\
\hline$<30$ & 18 & 5 \\
\hline $30-50$ & 32 & 15 \\
\hline$>50$ & 22 & 8 \\
\hline \multicolumn{2}{|c|}{ Table 3. Level of Microalbuminuria (mg/day) } \\
in both Sex and Risk of Developing IHD \\
\hline
\end{tabular}

In the present study, there was 54 males (75\%) and 23 females $(82.1 \%)$ with abnormal microalbuminuria. This shows that patients with microalbuminuria had higher risk of developing IHD ( $p<0.05)$. More Female patients in the present study had microalbuminuria $(82.1 \%)$ as compared to male patients $(75 \%)$. The incidence of microalbuminuria increased with increasing age except in $66-75$ age group in the present study.

\section{Relation of Microalbuminuria with Ischaemia/ Infarct Pattern}

77 patients $(77 \%)$ of the study group had microalbuminuria, which was statistically significant $(p<0.05)$. There was a slight increase in number of patients who presented with infarct pattern on ECG $(78.2 \%)$ compared to ischaemia pattern $(74.2 \%)$ in patients having microalbuminuria.

Relationship between Microalbuminuria, Hypertension and Ischaemia/ Infarct Pattern

Out of 48 patients of hypertension, 38 patients had microalbuminuria i.e. $79.2 \%$ of hypertensive had abnormal microalbuminuria. 29 out of 42 normotensive patients had microalbuminuria, i.e. $69 \%$.

\section{Relationship between Smoking, Microalbuminuria and} Ischaemia/ Infarct

There were 70 patients had history of smoking, out of which $77.4 \%$ smoker (54 patients) had microalbuminuria as compared to $75.8 \%$ non-smoker (22 patients) with microalbuminuria.

$74.1 \%$ of smokers with microalbuminuria presented with myocardial infarction compared to $61 \%$ of nonsmokers with microalbuminuria. 


\section{Relationship between Total Cholesterol,} Microalbuminuria, Ischaemia/ Infarct

Out of patients with abnormal total cholesterol level 25 patients had microalbuminuria $>30 \mathrm{mg}$ /day i.e. $86 \%$; whereas out of 71 patients with normal cholesterol 52 patients had microalbuminuria i.e. $73 \%$.

\section{DISCUSSION}

Ischaemic Heart Disease will become a major disease burden in India in upcoming years, therefore to target preventive strategies, risk stratification of the population should be effective. There are many reports emanating from the western literature about microalbuminuria as an independent risk factor for development of ischaemic heart disease.

Hitherto, microalbuminuria was considered as a marker of endothelial dysfunction in diabetes mellitus, but many studies have shown microalbuminuria is an effective marker of generalised vascular dysfunction even in non-diabetic population. This study was done to find out whether there is an association between IHD and Microalbuminuria in nondiabetic subjects.

In the present study, the diagnosis of IHD was made by ECG changes. De Bruyne MC et $\mathrm{al}^{11}$ have shown that ECG can be used to determine the presence of IHD in a population at large.

This study had $72 \%$ male patients compared to $28 \%$ female patients. This is in accordance with the knowledge that males are more prone for ischaemic heart disease than females. The mean age of the study population was $55.09 \pm 10.43$ years. It was $59.48 \pm 6.13$ years for females. All the females were in the post-menopausal age group, which shows that sex hormones has a protective effect as far as cardiovascular risk is concerned.

In this study, history of smoking was present in $70 \%$ of the study subjects indicating that smoking is an important risk factor for IHD. Umesh $\mathrm{N}$ Khot et al had found a prevalence of $41.6 \%$ in males and $29.5 \%$ in females in their study for smoking as a risk factor. ${ }^{12}$

$58 \%$ of patients in the present study had hypertension (51.3\% in males and $75 \%$ in females). This is much higher than the prevalence found by Umesh $\mathrm{N}$ Khot et al ${ }^{12}$ (38.4\% in males and $55.9 \%$ in females), but shows a similar trend.

$34 \%$ of the patients had hypertriglyceridaemia and $31 \%$ of patients had low HDL levels, which was similar to that obtained by Khot UN et $\mathrm{al}^{12}(39.6 \%$ of females and $34.1 \%$ of males had abnormal lipid parameters).

The present study showed that $77 \%$ of the patients with ischaemic heart disease had microalbuminuria, which shows a positive association.

In the PREVEND Study, ${ }^{13}$ Microalbuminuria was detected in $32.7 \%$ of Non-Diabetic IHD Patients.

In the HOPE Study, ${ }^{14}$ Microalbuminuria was detected in $14.8 \%$ of Non-Diabetics at baseline. This study showed that $20.4 \%$ of patients with microalbuminuria had Myocardial Infarction, Stroke or Cardiovascular cause of death as compared to $13.8 \%$ of these without microalbuminuria.

In our study, Microalbuminuria was detected in $77 \%$ of patients. This was probably due to our study had a cohort of IHD patients, in whom microalbuminuria was detected in contrast to above studies which was done in general populations.

\section{CONCLUSION}

Since there is the strong and independent association of elevated urine microalbumin with Ischaemic Heart Disease in non-diabetic subjects, as demonstrated in our study, it can be regarded as an important additional risk factor for Ischaemic Heart Disease and can be utilised as a simple, inexpensive and practical independent marker of Ischaemic Heart Disease.

\section{ACKNOWLEDGEMENTS}

We wish to acknowledge the administration, laboratory technicians and staff of Government Medical College and Associated Group of Hospitals, Kota, Rajasthan.

\section{REFERENCES}

[1] Antman EM, Loscalzo J. Harrison's Principles of internal medicine. 19th edn. McGraw-Hill 2015: p. 1578.

[2] Heart Disease and Stroke Statics 2016 Update, American Heart Association (http://www.heart.org).

[3] Toto RD. Microalbuminuria: definition, detection, and clinical significance. The Journal of Clinical Hypertension (Greenwich) 2004;(11 Suppl 3):2-7.

[4] Nguyen TT, Ellefson RD, Hodge DO, et al. Predictive value of electrophoretically detected lipoprotein (a) for coronary heart disease and cerebrovascular disease in a community-based cohort of 9,936 men and women. Circulation 1997;96(5):1390-7.

[5] Ridker PM, Cushman M, Stampfer MJ, et al. Inflammation, aspirin and the risk of cardiovascular disease in apparently healthy men. N Engl J Med 1997;336(14):973-9.

[6] Ridker PM, Hennekens CH, Buring JE, et al. C-reactive protein and other markers of inflammation in the prediction of cardiovascular in women. $\mathrm{N}$ Engl J Med 2000;342(12):836-43.

[7] Ma J, Hennekens $\mathrm{CH}$, Ridker PM, et al. A prospective study of fibrinogen and risk of myocardial infarction in the Physicians' Health Study. J Am Coll Cardiol 1999;33(5):1347-52.

[8] Christen WG, Ajani UA, Glynn RJ, et al. Blood levels of homocysteine and increased risk of cardiovascular disease: causal or casual? Arch Intern Med 2000;160(4):422-34.

[9] Viberti GC, Thomas SM. Searching for new coronary heart disease risk factors. Eur Heart J 2000;21:1905-6.

[10] Haffner SM, Stern MP, Gruber MK, et al. Microalbuminuria. Potential marker of increased cardiovascular risk factors in non-diabetic subjects? Arteriosclerosis 1990;10(5):727-31.

[11] De Bruyne MC, Kors JA, Hoes AW, et al. Both decreased and increased heart rate variability on the standard 10-second electrocardiogram predict cardiac mortality in the elderly: the Rotterdam study. American Journal of Epidemiology 1999;150(12):1282-8.

[12] Khot UN, Khot MB, Bajzer CT, et al. Prevalence of conventional risk factors in patients with coronary heart disease. JAMA 2003;290(7):898-904.

[13] Diercks GF, van Boven AJ, Hillege HL, et al. Microalbuminuria is independently associated with 
ischaemic electrocardiographic abnormalities in a large non-diabetic population. The PREVEND (Prevention of REnal and Vascular ENdstage Disease) study. European Heart Journal 2000;21(23):1922-7. angiotensin-converting-enzyme inhibitor, ramipril, on cardiovascular events in high-risk patients. The New England Journal of Medicine 2000;342(3):145-53.

[14] Heart Outcomes Prevention Evaluation Study Investigators, Yusuf S, Sleight P, et al. Effects of an 